\title{
Ensino de biologia na educação básica: produção de modelos didáticos e uso de
}

\section{práticas lúdicas}

\author{
Teaching biology in basic education: production of teaching models and use of ludic practices \\ Enseñanza de la biología en educación básica: producción de modelos didácticos y uso de prácticas
}

de juego

\section{Resumo}

Um dos grandes desafios para os professores de biologia ainda é a falta de materiais didáticos que possam facilitar e melhorar a compreensão dos alunos sobre o conteúdo ministrado. Diante disso, o objetivo deste trabalho foi apresentar o processo de construção de modelos didáticos com materiais de baixo custo para utilização em práticas metodológicas inovadoras no ensino de biologia na educação básica por meio da ludicidade. Nesta pesquisa de caráter exploratório e descritivo com natureza qualitativa e quantitativa, utilizamos materiais de baixo custo, além de objetos reutilizáveis para produzir modelos biológicos e desenvolver atividades práticas lúdicas. Com o desenvolvimento do trabalho foi possível confeccionar dois modelos biológicos didáticos: um modelo de membrana plasmática e outro de uma célula animal. Foi produzida uma revista em quadrinhos para estudo sobre transgênicos, além de serem desenvolvidas três atividades práticas utilizando matérias reutilizáveis (prática sobre o sistema sanguíneo $\mathrm{ABO}$, prática sobre a primeira Lei de Mendel e prática sobre divisão celular). Foi possível constatar que as atividades realizadas nas aulas favoreceram o processo de ensino e aprendizagem, tornando o aprendizado mais significativo, descontraído e dinâmico. Apontamos ainda que o professor precisa ter objetivos claros e concisos sobre os conteúdos a serem ministrados, para que assim possa explorar e aplicar atividades práticas através da ludicidade.

Palavras-chave: Ludicidade; Aulas inovadoras; Material didático; Ensino e aprendizagem.

\begin{abstract}
One of the great challenges for biology teachers is still the lack of teaching materials that can facilitate and improve students' understanding of the content taught. Therefore, the objective of this work was to present the process of building didactic models with low-cost materials for use in innovative methodological practices in teaching biology in basic education through playfulness. In this exploratory and descriptive research with a qualitative and quantitative nature, we use low-cost materials, in addition to reusable objects to produce biological models and develop practical recreational activities. With the development of the work, it was possible to make two didactic biological models: a plasma membrane model and another for an animal cell. A comic book was produced for the study of transgenics, in addition to the development of three practical activities using reusable materials (practice on the ABO blood system, practice on Mendel's first law and practice on cell division). It was possible to verify that the activities carried out in the
\end{abstract}


classes favored the teaching and learning process, making learning more meaningful, relaxed and dynamic. We also point out that the teacher needs to have clear and concise objectives about the content to be taught, so that he can explore and apply practical activities through playfulness.

Keyword: Playfulness; Innovative classes; Courseware; Teaching and learning.

\section{Resumen}

Uno de los grandes desafíos para los profesores de biología sigue siendo la falta de materiales didácticos que puedan facilitar y mejorar la comprensión de los contenidos impartidos por los estudiantes. Por tanto, el objetivo de este trabajo fue presentar el proceso de construcción de modelos didácticos con materiales de bajo costo para su uso en prácticas metodológicas innovadoras en la enseñanza de la biología en la educación básica a través del juego. En esta investigación exploratoria y descriptiva de carácter cualitativo y cuantitativo, utilizamos materiales de bajo costo, así como objetos reutilizables para producir modelos biológicos y desarrollar actividades lúdicas prácticas. Con el desarrollo del trabajo, fue posible realizar dos modelos biológicos didácticos: un modelo de membrana plasmática y otro de célula animal. Se produjo un cómic para estudiar los transgénicos y se desarrollaron tres actividades prácticas utilizando materiales reutilizables (práctica sobre el sistema sanguíneo ABO, práctica sobre la primera Ley de Mendel y práctica sobre división celular). Se pudo constatar que las actividades realizadas en las clases favorecieron el proceso de enseñanza y aprendizaje, haciendo el aprendizaje más significativo, relajado y dinámico. También señalamos que el docente debe tener objetivos claros y concisos sobre el contenido a enseñar, para que pueda explorar y aplicar actividades prácticas a través de la alegría.

Palabras clave: Alegría; Clases innovadoras; Material didáctico; Enseñando y aprendiendo.

\section{Introdução}

Tomando como ponto de partida uma citação de Freire (1996), ao dizer que o professor crítico é um "aventureiro" responsável, predisposto à mudança, à aceitação do diferente, num sentido de mudança e criticidade, deparamo-nos com algo que nos desafiou na prática docente referente ao ensino de biologia: construir e implementar aulas diferenciadas, que atraiam atenção dos alunos e despertem o interesse pela disciplina.

As metodologias alternativas têm sido empregadas como estratégias com o objetivo de desenvolver no aluno habilidades e competências profissionais necessárias para a apropriação do conhecimento (Cardozo et al., 2016). Tesori \& Martins (2018) corroboram dizendo que a produção de materiais pedagógicos nos permite superar os obstáculos como a falta de infraestrutura e materiais pedagógicos que as escolas públicas enfrentam, ao mesmo tempo em que proporcionam aos educandos a oportunidade de manipular e explorar materiais, ampliando os conhecimentos adquiridos em sala de aula.

Ensinar Biologia é uma tarefa complexa, exige que professor e aluno lidem com uma série de palavras diferentes, com pronúncias difíceis e escrita que diverge da linguagem comumente usada pela população (Duré et al., 2018), desta forma, o uso do divertimento no ensino de Biologia pode ser considerado didaticamente como estratégia de ensino, por levar o aluno a desenvolver suas habilidades e potencialidades, estimula o pensamento, a criatividade, além do prazer em aprender e interagir de forma satisfatória com todos na sala (Ferreira \& Santos, 2019). Nesse sentido é importantíssimo, por exemplo, associar a teoria com a prática para um melhor entendimento dos conteúdos estudados, pois a aula prática ajuda no desenvolvimento cognitivo do aluno.

É nesse lócus que se insere nossa problemática. Afinal, é possível inovar as aulas de biologia por meio da ludicidade? Como os alunos e professores analisam a construção de modelos didáticos? A elaboração de materiais e práticas mais inovadoras? O conteúdo por meio do lúdico? Tais questões nos direcionam para uma discussão sobre ensino de biologia e ludicidade, não como a resolução final dos desafios do ensino de biologia, mas como uma alternativa para a superação de um ensino canônico e tradicional. Não é nosso objetivo apresentar respostas prontas ou modelos para serem minuciosamente replicados, mas direcionar os professores de biologia a repensarem suas práticas e metodologias.

Através de atividades diferenciadas, que podemos considera-las inovadoras, por meio da criação de modelos biológicos, brincadeiras e interação com os demais colegas, que o discente terá mais facilidade na compreensão dos conteúdos da disciplina, percebendo que existe um mundo amplo de seres a serem estudados. Diante disto, os modelos didáticos contribuem para o 
processo de ensino e aprendizagem de forma bastante efetiva (De Oliveira et al., 2015) e a ludicidade pode facilitar a compreensão e o desempenho do indivíduo durante uma aula em que o professor esteja aplicando uma atividade diferenciada relacionada a algum assunto da Biologia, deixando o estudante mais atento, mais envolvido e, consequentemente, aprendendo com mais facilidade (Cartaxo, 2013).

Na maioria das escolas há escassez de material e falta de estrutura laboratorial para realização de aulas práticas nas disciplinas de Ciências e Biologia (Silva; Teixeira \& Pereira, 2020). Diante dessas dificuldades, materiais didático-pedagógicos são utilizados por professores como forma de instrumentos auxiliares para a prática pedagógica. Nessa perspectiva, o presente estudo objetiva apresentar o processo de construção de modelos didáticos com materiais de baixo custo para utilização em práticas metodológicas inovadoras no ensino de biologia na educação básica por meio da ludicidade, na perspectiva de melhorar o ensino dos temas em questão.

\section{Ensino de Biologia e Ludicidade: Enfoques e Finalidades}

O currículo de Biologia para o ensino médio coloca ao professor o desafio de trabalhar com uma enorme variedade de conceitos, com conhecimentos sobre toda uma diversidade de seres vivos, processos e mecanismos que, a princípio, se apresentam distantes do que a observação cotidiana consegue captar (Duré et al., 2018). Desta forma, o professor de Biologia deve estar disposto para empreender novos conhecimentos, reconhecer que a mudança de sua ação depende de uma formação contínua e necessária, a construção coletiva de novas alternativas educativas, apropriação da cultura científica e possibilidade de usar novas metodologias em sala de aula. Pereira et al. (2020) acrescentam que o estudo da Biologia é de fundamental importância para a compreensão do funcionamento dos seres vivos. No entanto, os alunos apresentam dificuldades na assimilação dos conteúdos dessa disciplina.

Para Nascimento et al. (2015) no ensino de biologia, as metodologias utilizadas pelos profissionais podem ser uma maneira de superar as dificuldades encontradas no exercício docente, principalmente no que diz respeito aos recursos utilizados para auxiliar a explanação do conteúdo. Recursos como: atividades de experimentação, aulas lúdicas, o desenvolvimento de projetos, jogos, seminários, debates e simulações, são propostas que possibilitam o fortalecimento do vínculo professor e aluno.

O professor de Biologia no ensino médio além de explanar conteúdos abstratos de cunho cientifico vinculados ao mundo acadêmico, não pode deixar de abordar conteúdos de caráter utilitário, ou seja, que atenda às necessidades sociais dos alunos. Nesse sentido, para Krasilchik (2008) a biologia pode ser uma das disciplinas mais relevantes e merecedora da atenção dos alunos, ou uma das disciplinas mais insignificantes e pouco atraente, dependendo da forma como é ensinada. Diversas criações, dentro desta área, foram inventadas com o intuito de facilitar o aprendizado, pois, como disciplina, apresenta-se de forma rica e ampla (Ferreira \& Santos, 2019).

O ensino de Biologia pode ser considerado um meio de nortear o posicionamento do aluno frente a questões polêmicas e essenciais para a população, tendo um importante papel no desenvolvimento das noções de ambiente, formações, relações existentes entre seres vivos e não vivos e, principalmente, fomentar as discussões que nos permitem entender o universo do ponto de vista das ciências que buscam sua validação no próprio objeto de estudo (Borba, 2013). Nesta perspectiva de ensino, o lúdico entra como um termo utilizado por alguns professores em sala de aula relacionado a divertimento, brincadeiras, atividades criativas, permitindo que os alunos aprendam a desenvolver suas capacidades por meio de brincadeiras, usando a imaginação. Ferreira \& Santos (2019) definem a ludicidade como um potente veículo de aprendizagem em Biologia, visto que permite vivenciar a aprendizagem como processo social.

Costa \& Pinho (2008) reforçam que é preciso deixar claro, que o uso da ludicidade não se apresentará como uma solução mágica para o ensino de Biologia, mas se constituirá em algo diferente, inovador e motivador em relação ao aprendizado do conteúdo a ser abordado. O professor irá aplicá-lo em função dos objetivos que deseja alcançar. Outro ponto a considerar, é que 
a Biologia apresentada em sala de aula, por vezes, ainda é vista como uma disciplina repleta de conteúdos e nomes que não têm necessidade de serem decorados, ficando distante da vivência do aluno, com isso, a aprendizagem não ocorre ou ocorre de maneira equivocada, pois, conteúdos desvinculados do cotidiano e ausência de aulas práticas, são problemas recorrentes no ensino de biologia (Araújo, 2014).

Amaral et al. (2015) corroboram afirmando que as aulas de Biologia necessitam muitas vezes de atividades práticas, no entanto, nem sempre há recursos necessários disponíveis para que sejam concretizadas. Nestes casos, a estratégia de confecção de materiais didáticos feitos com materiais acessíveis e de baixo custo, pode apresentar-se como uma solução para minimizar a falta de infraestrutura na escola de ensino básico. Uma alternativa para a falta de laboratórios nas escolas públicas seria a montagem de laboratórios que contivessem modelos didáticos que contemplassem os conteúdos e, dessa forma, pudessem trazer uma visão mais aproximada desse mundo abstrato aos estudantes do Ensino Médio, na ausência de equipamentos de alto custo (Orlando et al.,2009).

A construção de materiais lúdicos auxilia o educando na aprendizagem de conceitos em aulas que não sejam apenas teóricas, mas também práticas. Usar o lúdico para atrair a atenção do aluno, tirá-lo da tensão da sala de aula e mostrá-lo que o assunto não é tão difícil de ser compreendido. É relevante que estas estratégias de ensino sejam adotadas pelos professores de biologia.

\section{Inovando Através do Lúdico: Construção e Reflexão}

O estudo caracteriza-se como uma pesquisa de caráter exploratório e descritivo com natureza qualitativa e quantitativa. A opção por este tipo de pesquisa se dá de acordo com os preceitos utilizados por Soares (2019) e por tratar-se de um trabalho desenvolvido no espaço educativo que envolve diferentes sujeitos e aspectos do processo como, o professor, o aluno, o cotidiano escolar, as metodologias aplicadas na sala de aula, os recursos didáticos utilizados, o estado físico da instituição e o ensino e aprendizagem.

A pesquisa foi realizada em uma escola pública de ensino fundamental e médio localizada no município de AbaetetubaPA, onde ocorreu a confecção dos materiais lúdicos de apoio com estudantes do $1^{\circ}$ e $2^{\circ}$ ano do ensino médio e professores de biologia da respectiva turma. A escola oferta vagas ainda para o nível Fundamental ( $6^{\circ}$ ao $9^{\circ}$ ano), Médio, Educação de Jovens e Adultos e Educação Especial.

Após aplicação de todas as práticas e aulas com modelos propostos, realizamos uma entrevista semiestruturada com a professora titular da turma que acompanhou todo o processo, para que assim, pudéssemos obter dados sobre a eficácia da metodologia utilizada, sua viabilidade no ensino de biologia e sobre a necessidade de ajustes em determinadas práticas e/ou modelos produzidos. Por questões éticas, foi disponibilizado um termo de livre e esclarecido para todos os alunos que participaram das aulas e consequentemente das aplicações. O mesmo termo foi disponibilizado e assinado também pela professora da turma que participou da entrevista.

\subsection{Confecção e Aplicação dos Modelo Didáticos}

Foram construídos diferentes modelos biológicos e desenvolvidas práticas pedagógicas lúdicas para abordagem de conteúdos de biologia, como: membrana plasmática, divisão celular, biotecnologia e genética. A escolha destes conteúdos foi pautada na Matriz Curricular da Base Nacional Comum Curricular - BNCC para o ensino médio, tais temáticas apresentarem dificuldades na preparação de aulas práticas pelos professores e consequentes dificuldades de entendimento pelos alunos. Para a produção, foi utilizado material de baixo custo ou reutilizáveis, como: EVA, cartolina, massinha de modelar, cuba de ovo, miçangas, copos transparentes, caixa de papelão, lápis de cor, linha de lã, cola de isopor e TNT. 


\subsubsection{Construção do Modelo de Membrana Plasmática}

A membrana plasmática é uma estrutura que não pode ser vista a olho nu, podendo ser visualizada apenas com auxílio de um microscópio. Na tentativa de reproduzir as estruturas de sua composição, foi confeccionado um modelo didático de membrana utilizando materiais reutilizáveis. A montagem da estrutura foi realizada aos poucos para que os alunos pudessem entender seus mecanismos e acompanhar todo o processo. Os materiais utilizados foram caixas de papelão com dimensões média, cubas de ovo, EVA, TNT, miçangas, arames, cartolina, cola de isopor e tala para churrasco.

Inicialmente a caixa de papelão foi encapada com TNT, em seguida as cubas de ovos foram coladas por cima e por baixo da caixa. As miçangas e os arames foram dispostos acima da cuba de ovos para representarem as glicoproteínas, carboidratos e glicolipídios. Seguidamente as talas para churrasco junto com o EVA cortados em pequenos círculos representam as proteínas de membrana (Figura 1).

Figura 1 - Construção do modelo de membrana plasmática usando material reciclável.

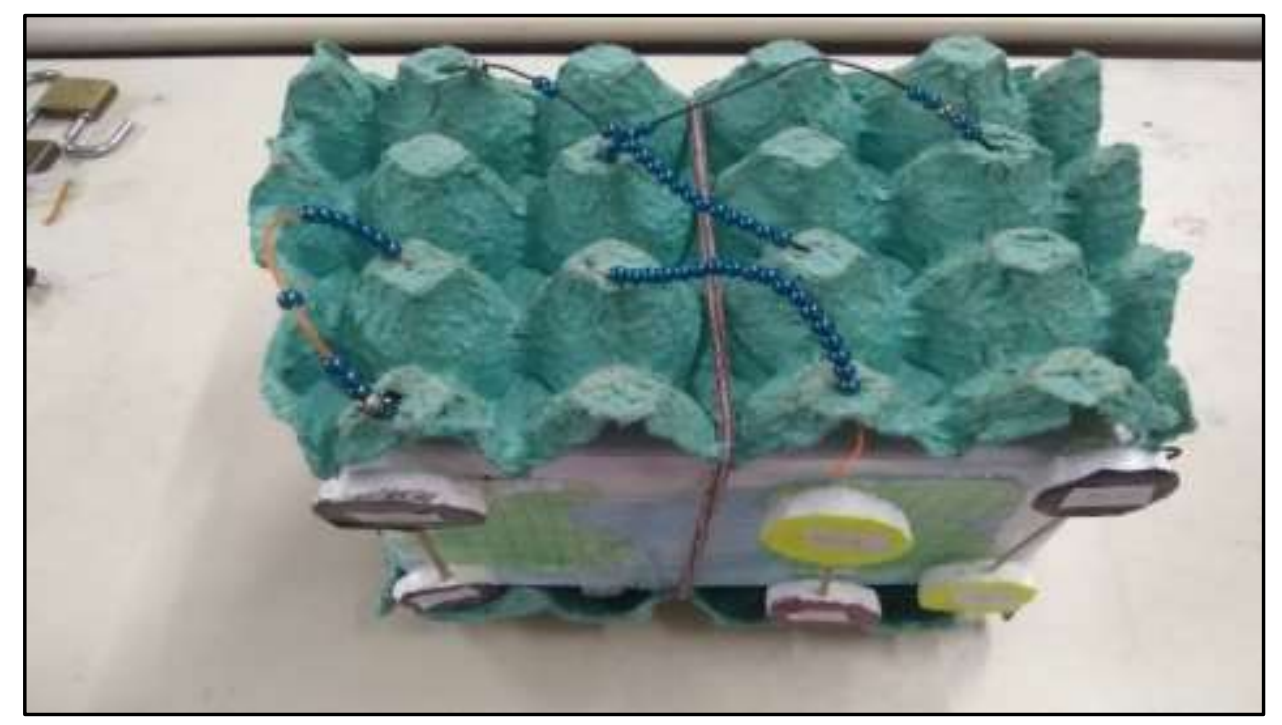

Fonte: Arquivo pessoal (2019).

\subsubsection{Construção do Modelo de Célula Animal}

O estudo da célula em modelos, possibilita uma visualização melhor de suas estruturas internas e externas facilitando a compreensão da sua funcionalidade. Foram construídos modelos didáticos de célula animal juntamente com os alunos, com a finalidade de suprir tal necessidade. Ao término da explanação sobre o conteúdo, a turma foi dividida em grupos para a criação dos modelos (Figura 2).

Para a confecção da célula animal foram utilizadas quatro Folhas de EVA branco, duas caixas de massinha de modelar de $180 \mathrm{~g}$ com doze cores, uma pistola com cola quente e duas tesouras. A folha de EVA foi cortada em círculos, em seguida com a cola quente foi produzido a borda do círculo que representa a membrana plasmática da célula. A massinha de modelar foi utilizada para fazer as organelas de diferentes cores e formas. 
Figura 2 - Construção dos modelos de célula animal.

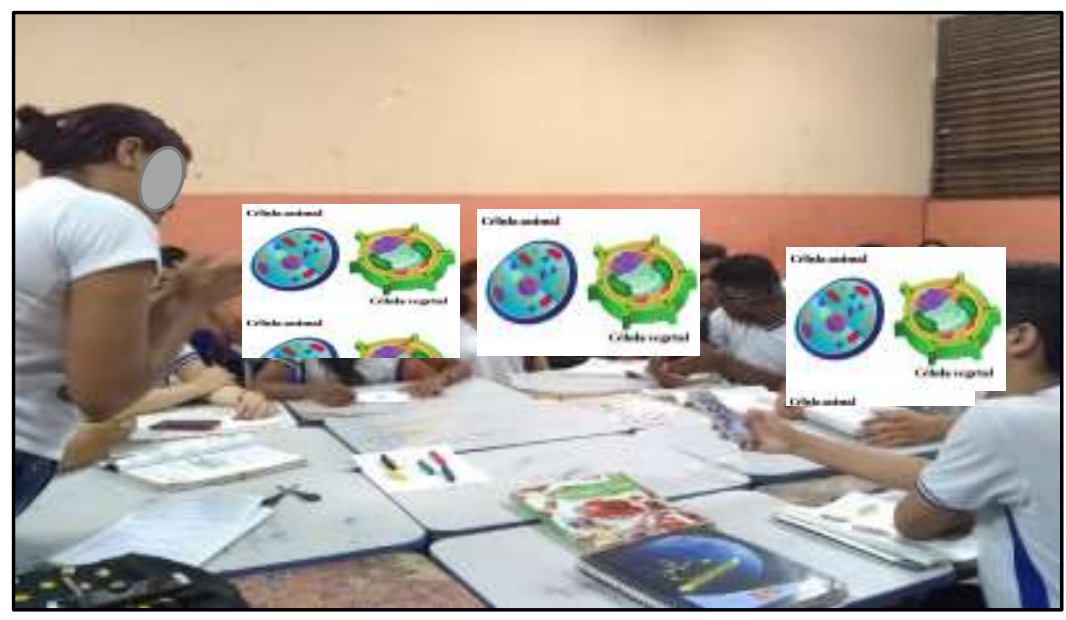

Fonte: Arquivo pessoal (2019).

\subsubsection{Produção de uma Revista em Quadrinhos}

A produção de uma revista em quadrinhos foi utilizada como ferramenta para despertar o interesse dos alunos acerca de alimentos transgênicos, bem como, promover um ensino de biologia mais dialógico, crítico e emancipador. É uma metodologia que articula diferentes posicionamentos e estimula o debate social, função do ensino aliada à aprendizagem. Do Nascimento et al. (2020) apontam que a dificuldade na abordagem da biotecnologia aliada à falta de recursos didáticos e metodologias apropriadas, têm proporcionado problemas na compreensão e assimilação dos conteúdos relacionados. O aplicativo usado para criação dos personagens foi o "Cômica”, que é um aplicativo de edição de fotos de aparelho celular disponível no google play. Para edição utilizamos o programa de computador Microsoft Word 2013 que é um programa de criação de textos e documentos com diversas ferramentas.

Primeiramente com o auxílio de um aparelho celular, foram tiradas diversas fotos no pátio da escola, em diversos ângulos e diferentes movimentos com os lábios, vários gestos que pudessem transmitir emoções e movimentos de fala. Após as fotos já estarem prontas, seguimos para a segunda etapa que foi a edição destas no aparelho celular com o aplicativo cômica já instalado. Com isso, as fotos foram enviadas para o notebook onde foram editadas no Microsoft Word 2013 (Figura 3 ) utilizando as ferramentas de formas, como: balões e quadros. Em seguida, criamos caixas de texto para serem escritas as falas dos personagens. Após a edição, a revista passou por uma revisão textual e foi impressa para ser usada nas aulas com os alunos.

A aplicação da revista foi realizada com turmas do segundo ano do turno tarde em uma aula sobre biotecnologia, em que foram abordados os conceitos básicos relacionados a transgênicos e suas aplicações. 
Figura 3 - Edição da Revista em Quadrinhos (RQ) sobre alimentos transgênicos.

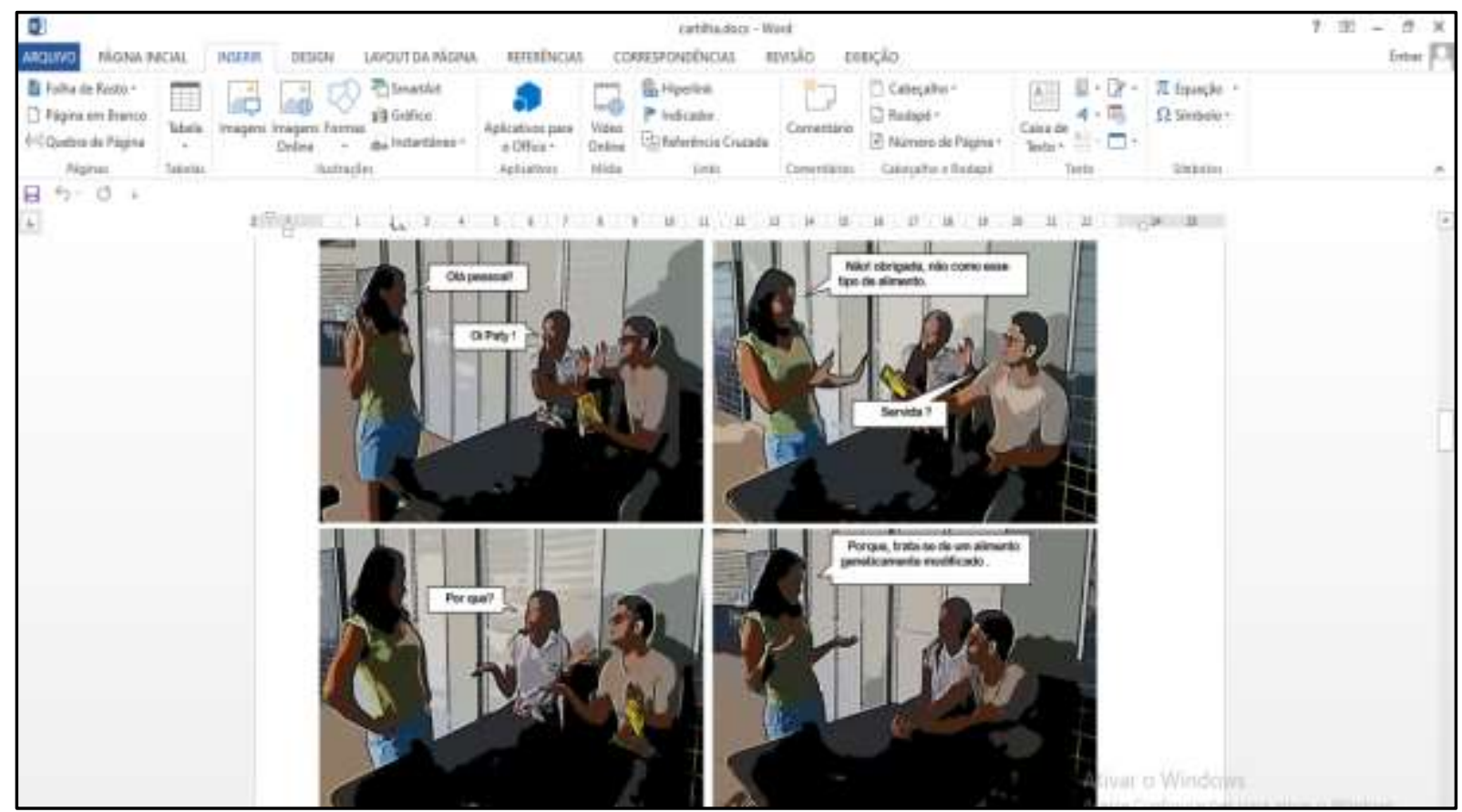

Fonte: Arquivo pessoal (2019).

\subsubsection{Prática Lúdica sobre o Sistema Sanguíneo ABO}

O sistema sanguíneo ABO faz parte do conteúdo de genética para o ensino médio, sendo considerado um assunto de suma importância no cotidiano. Porém, acredita-se haver certa dificuldade de compreensão do assunto ao estudá-lo apenas de forma teórica. Com isso, a prática realizada simula uma transfusão sanguínea entre diferentes indivíduos. Os materiais utilizados foram quatro copos transparentes, uma caneta, um rolo de fita crepe, quatro garrafas pets contendo respectivamente água, suco de uva, suco de laranja e a última utilizada para misturas. Cada copo foi identificado com os tipos sanguíneos (A, B, AB e O) na sequência foram colocados em uma superfície para serem visualizados pelos alunos.

Os discentes então foram divididos em quatro equipes, cada um representando um tipo sanguíneo. Os Tipos sanguíneos A e B foram representados por sucos em pó de sabores laranja e uva respectivamente. Cada equipe recebeu um copo transparente com água representando um vaso sanguíneo (o copo) e o plasma (a água).

Cada equipe escolheu um representante para ir à frente da sala com seu respectivo copo, com o desafio de responder, mediante a pergunta realizada pelo professor: Equipe Tipo A: A que tipos sanguíneos o tipo A pode doar e de quais tipos poderá receber? Equipe Tipo B: A que tipos sanguíneos o tipo B pode doar e de quais tipos poderá receber? Equipe Tipo AB: A que tipos sanguíneos o tipo AB pode doar e de quais tipos poderá receber? Equipe Tipo O: A que tipos sanguíneos o tipo O pode doar e de quais tipos poderá receber?

Após as devidas respostas foi adicionado uma pequena quantidade do refresco tipo O (incolor) nos demais copos para provar que este grupo é considerado o doador universal. Isso ocorre porque não há alteração da cor no copo das demais equipes. Sequencialmente foi adicionado uma pequena quantidade de qualquer um dos tipos de refresco ao copo que representa o tipo O, para que percebam a alteração da cor, seguindo com os demais tipos sanguíneos realizando diversas combinações. 


\subsubsection{Prática Lúdica sobre a Primeira Lei de Mendel}

Mendel, considerado como um pioneiro no estudo da genética, estudou a transmissão das características de uma geração para outra utilizando ervilhas. Visando dificuldades na realização de atividades práticas sobre o assunto, realizamos uma atividade lúdica que poderá auxiliar na assimilação deste conteúdo.

No primeiro momento foi realizada uma breve revisão sobre o experimento de Mendel e a forma como ele observou a transmissão de características nas ervilhas, envolvendo os conceitos de genótipo, fenótipo, homozigoto e heterozigoto. Os materiais utilizados na prática foram: uma folha de cartolina branca, duas tesouras, uma caixa de lápis de cor e um rolo de fita durex. A folha de cartolina foi cortada em círculos, os círculos foram pintados de amarelo e verde para representar as ervilhas e assim demonstrar os conceitos de Genótipos (RR, Rr, rr) e Fenótipos (amarelo e verde) propostos no cruzamento de Mendel (Figura 4-B).

Num segundo momento, confeccionamos o quadro de Punnett juntamente com os alunos, utilizando os materiais: uma folha de cartolina da cor branca, régua, lápis de cor, doze folhas de papel A4 e fita durex. O quadro de Punnett foi desenhado na cartolina com o uso de lápis e régua e os genótipos (AA, Aa, aa) foram desenhados na folha de papel A4 (Figura 4-A).

Figura 4 - Montagem da Prática Lúdica sobre a Primeira Lei de Mendel, montando o quadro de Punnett (A), confeccionando a representação das ervilhas (B).

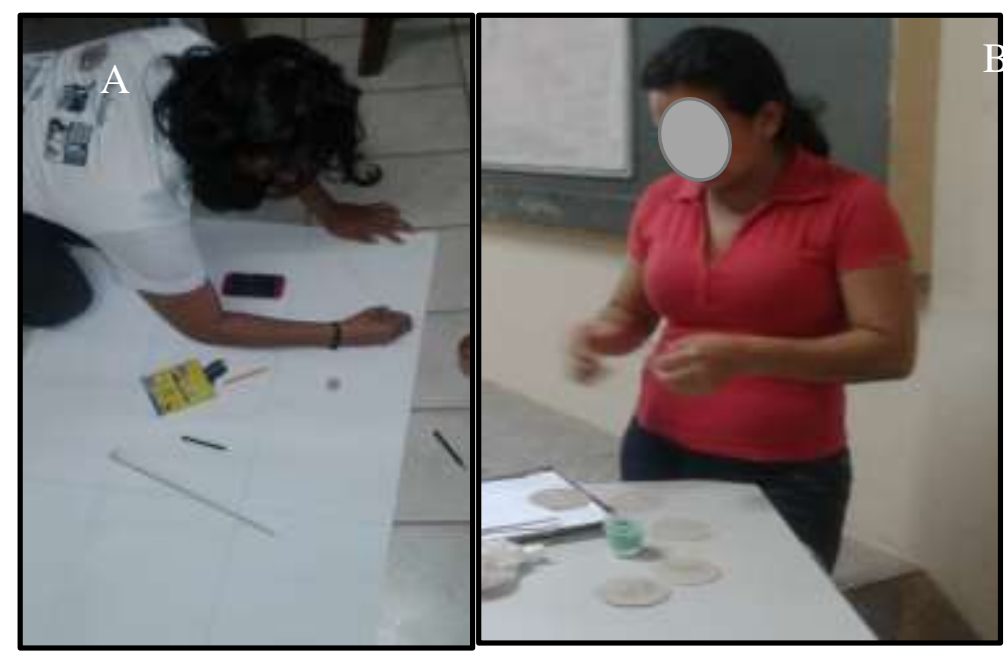

Fonte: Arquivo pessoal (2019).

\subsubsection{Prática Lúdica sobre Divisão Celular}

A divisão celular implica na produção de novas células, sendo fundamental para diversos processos como o desenvolvimento embrionário, o crescimento do organismo, a regeneração ou renovação tecidual, reprodução assexuada e a formação de gametas. Por ser um assunto que exige bastante atenção, torna-se extenso e muitas vezes cansativo para os alunos.

Para o desenvolvimento da atividade proposta, em um primeiro momento foi realizada uma aula expositiva e introdutória sobre o assunto divisão celular, demostrando os principais estágios tanto da divisão por mitose quanto por meiose. Em seguida, para a elaboração dos modelos didáticos foram utilizados caixas de massinha de modelar de $180 \mathrm{~g}$, cartolina, fio de lã e papel EVA (Figura 5). Com os materiais em mãos, os alunos foram divididos em grupos com três ou quatro integrantes cada, onde todos deveriam participar da atividade. Esta consistia em reproduzir os movimentos realizados pelos cromossomos no momento da divisão celular, destacando características básicas e estruturais das diferentes fases do processo de divisão. 
Figura 5 - Montagem dos modelos representativos dos processos de divisão celular por mitose e meiose.

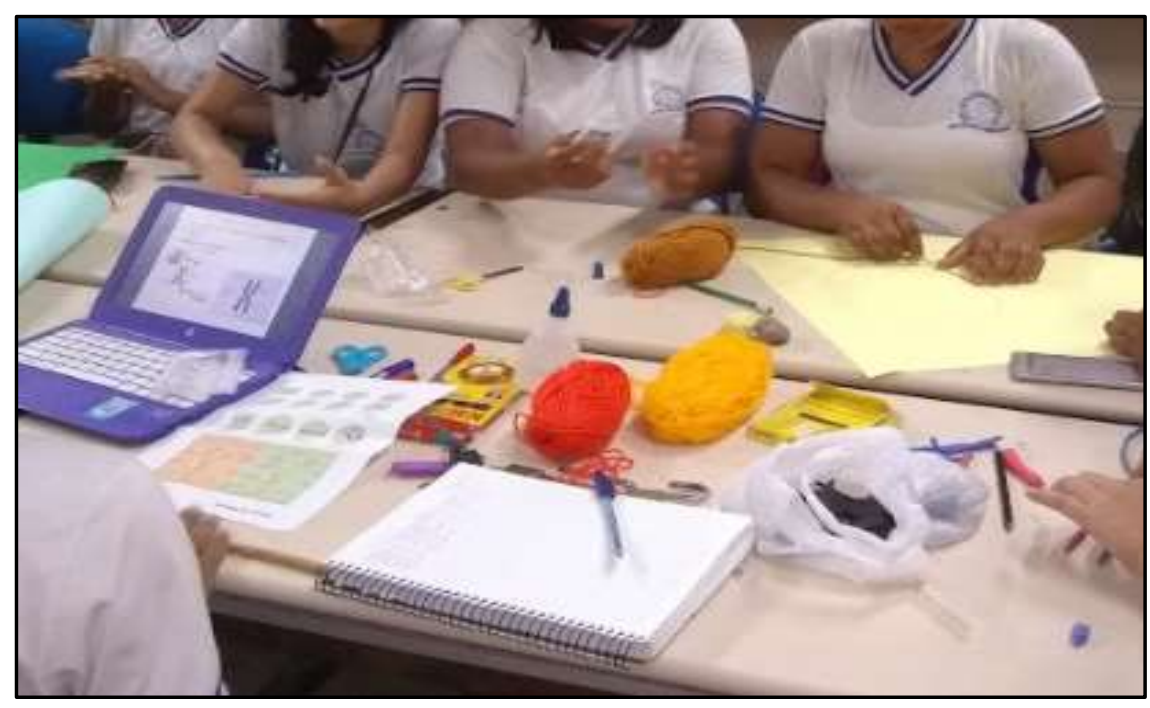

Fonte: Arquivo pessoal (2019).

As massinhas de modelar serviram para formar os cromossomos demonstrando seus movimentos nos processos de mitose e meiose, enquanto a cartolina foi utilizada de base para os cromossomos, a lã foi utilizada para formar a borda da célula e as fibras dos fusos, ao decorrer da atividade foi discutido com os alunos o objetivo de cada processo, associando-o ao cotidiano destes.

\section{Resultados e discussão}

\subsection{Produções e aplicações}

Com o desenvolvimento do trabalho foi possível confeccionar dois modelos didáticos, um para a membrana plasmática (Figura 6) e outro para a célula animal (Figura 7) foi produzido uma revista em quadrinhos para estudo dos transgênicos, além de serem desenvolvidas três atividades práticas lúdicas utilizando matérias reutilizáveis (prática sobre o sistema sanguíneo ABO, prática sobre a primeira Lei de Mendel e a prática sobre a divisão celular). 
Figura 6 - Modelos da membrana plasmática mostrando os glicolipídios presentes na membrana (1), a estrutura em bicamada lipídica da membrana (2), colesterol associado a membrana (3) e proteínas associadas a dupla camada de lipídeos (4).

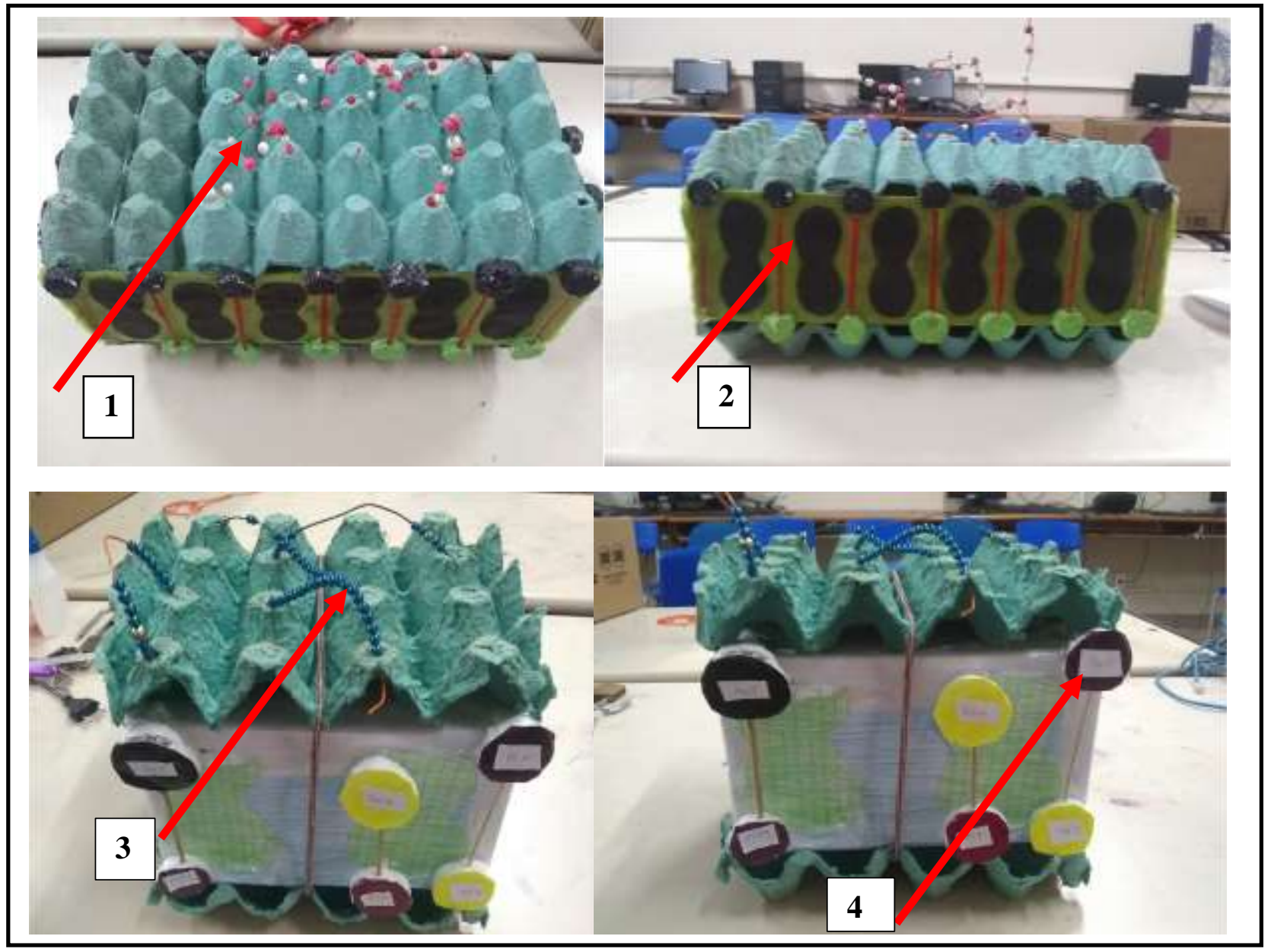

Fonte: Arquivo pessoal (2019).

Para Costa et al. (2017) os modelos didáticos mostram-se como uma alternativa bastante viável devido à possibilidade que eles trazem de disponibilizar, aos estudantes, uma visão mais aproximada do que é encontrado nos livros. Neste sentido, ao elaborar um modelo junto com os discentes sentimos ainda mais êxito, pois os mesmos se envolvem na realização da atividade de forma que a prática se torna uma atividade leve e prazerosa de se realizar.

Figura 7 - Modelos de células animal construídos pelos alunos da turma.

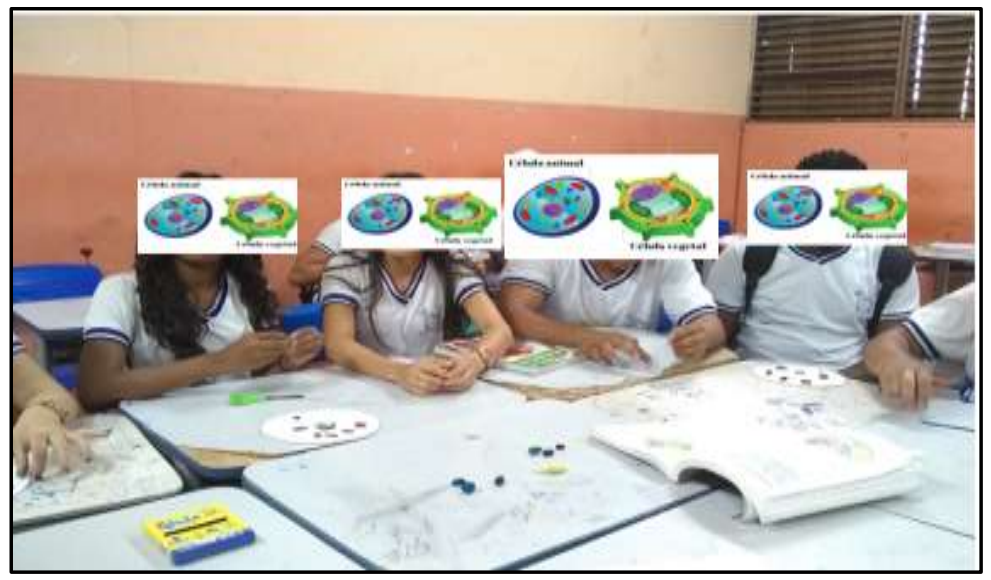

Fonte: Arquivo pessoal (2019). 
Ao associarmos a teoria com a prática, os alunos tiveram a oportunidade de moldar, identificar a função de cada parte e visualizar a localização de cada estrutura. Foi um momento de socialização e troca de conhecimento entre os envolvidos. É preciso ir além de uma aula expositiva e utilizar novas ferramentas didáticas por meio das quais o aluno tenha a oportunidade e o prazer de aprender com entusiasmo, pois o ensino deve estar voltado ao progresso intelectual do educando, não se resumindo apenas na memorização, mas também no ato de pesquisar, ler e socializar as ideias adquiridas, interagindo com colegas e professores (Porto et al., 2009).

A produção da Revista em Quadrinhos foi considerada algo bastante diferenciado e lúdico para a turma. A criação foi pautada em um material com diálogos curtos e cenas cotidianas, onde podíamos explicar de forma simples conceitos básicos relacionados aos transgênicos. Mehes e Maistro (2011) concordam que as tirinhas, quadrinhos ou charges, como recurso didático, se constituem num magnífico meio para discutir conceitos científicos, para refletir sobre cidadania, sobre ética, sobre respeito para com o outro, de forma interessante e de maneira lúdica. Em trabalho realizado com a ludicidade, Pereira et al. (2020) destacam que durante a aplicação da estratégia lúdica, os alunos demonstraram um grande interesse pelo assunto, pois estavam mais à vontade e participativos, observação também considerada um ponto positivo neste trabalho.

Com a prática sobre o sistema sanguíneo $\mathrm{ABO}$ percebemos que algo rápido e simples muitas vezes é o suficiente para chamar a atenção dos alunos e despertar o interesse destes para o tema a ser trabalhado, concordando assim com Cardoso (2013) quando afirma que atividades práticas podem ser grandes aliadas no momento de apresentar um assunto, reforçá-lo ou torná-lo mais significativo. Silva; Teixeira \& Pereira (2020) em trabalho com construção de modelos didáticos, destacam que o interesse do aluno foi diretamente proporcional à sua interação com o tema proposto, o que torna a prática docente mais dinâmica, muitas vezes fugindo do prévio planejamento.

Algo semelhante aconteceu também com a atividade lúdica sobre a primeira Lei de Mendel. Nesta aplicação percebemos que o clima na sala foi de diversão e descontração, os alunos conseguiram realizar os cruzamentos de forma dinâmica por meio do quadro de Punnet facilitando a resolução dos exercícios propostos pela professora em um segundo momento. Isso é corroborado por Do Nascimento et al (2020), quando afirmam que a inserção de aulas práticas ajuda a manter o interesse, compreensão de conceitos básicos, instiga a capacidade de resolver problemas, envolve os discentes em investigações científicas e desenvolve habilidades.

Na prática sobre mitose e meiose (Figura 8) foi possível observar momentos divertidos, prazerosos e bem dinâmicos. Ressaltamos a preocupação de cada aluno nos detalhes e relevos de cada estrutura, bem como sua funcionalidade, quando várias questões sobre a importância deste processo biológico para a vida dos seres vivos foram levantadas no momento da atividade. Nesse sentido, os modelos didáticos agregam valores significativos na aprendizagem dos alunos, pois instigam, levantam questionamentos e possíveis resoluções de problemas, além de aproximar ideias e trocas de vivencias (Silva; Teixeira \& pereira, 2020). 
Figura 8 - Modelos construídos para os processos de divisão por mitose e meiose.

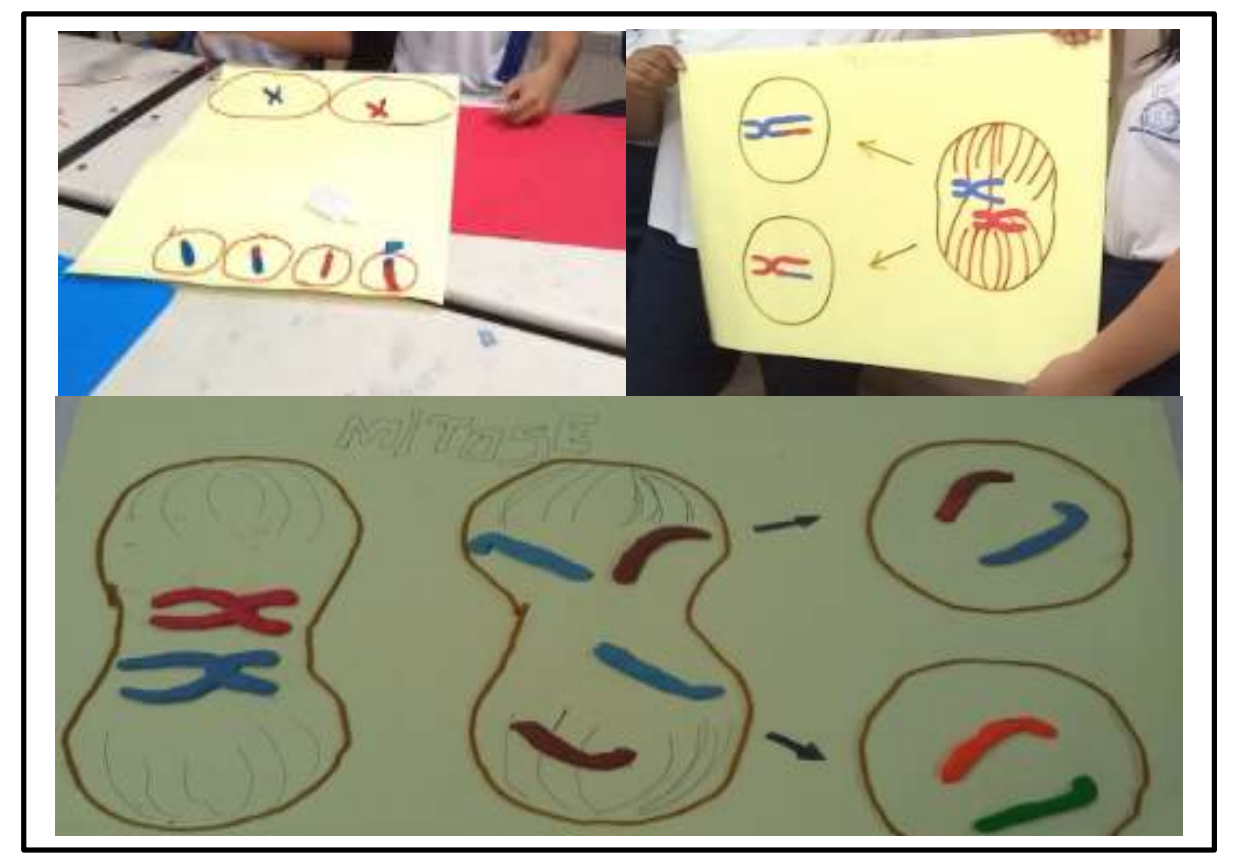

Fonte: Arquivo pessoal (2019).

Ressaltamos que o fato de termos disponibilizado o material necessário para que os discentes fossem construindo os modelos ao mesmo tempo que o professor direcionava a prática fez total diferença, uma vez que não se caracterizou como um momento de demonstração, em que os alunos apenas visualizaram o professor fazendo algo, ou como um momento de repetição, em que os alunos repetem o que o professor faz. As atividades práticas desenvolvidas foram construídas e executadas em conjunto, entre professora e discentes.

\subsection{Avaliação dos modelos e práticas aplicadas}

A professora titular da turma acompanhou todo o processo de montagem e desenvolvimento das aulas. Ressaltamos que a entrevista com a professora em questão, aconteceu de forma presencial, porém seguindo todas as recomendações de distanciamento e uso de equipamentos de proteção de acordo com recomendações da Organização Mundial da Saúde (OMS), uma vez que já nos encontrávamos em situação de pandemia. Já as aplicações ocorreram antes do surgimento da pandemia e consequente inserção do formato de ensino remoto. Nos trechos da entrevista abaixo, optamos por não identificar a entrevistada, utilizando o código (P1) para destacar suas falas.

O primeiro questionamento que fizemos a docente, foi de que forma a metodologia aplicada contribuiu para o desempenho cognitivo dos alunos, destacando o trecho de resposta:

Bom, quando falamos em atividades lúdicas, estamos dando referência a atividades que saem do cotidiano de sala de aula do aluno, desta forma podemos perceber que a atividade surtiu as necessidades do objetivo estabelecido, quando o aluno começa a interagir e ser mais participativo, podemos perceber esse desenvolvimento quando passamos alguma atividade avaliativa, é notório que o aluno conseguiu assimilar o conteúdo com êxito. É perceptível que este tipo de metodologia adiciona e melhora o desenvolvimento cognitivo do aluno pois ele consegue assimilar o conteúdo e fixar $(P 1)$. 
A fala da professora, vai de encontro com o pensamento de Cartaxo (2013) quando afirma que o lúdico proporciona uma nova motivação para aquisição do conhecimento, envolvendo o aluno de forma diferenciada, mudando a rotina monótona da sala de aula, fazendo com que ele se interesse mais e que as dificuldades encontradas em relação aos assuntos sejam assimiladas com mais facilidade.

Diante da resposta anterior da professora, perguntamos se os modelos biológicos confeccionados alcançaram o objetivo de demostrar as estruturas microscópicas relacionadas aos conteúdos trabalhados.

Sim, em nossa escola não temos suporte laboratorial para realizarmos práticas, para mostrarmos estruturas microscópicas que a biologia exige, estão quando vocês trouxeram os modelos biológicos o aluno pode ter acesso a visualização das estruturas que não podem ser vistas a olho nu. Esse tipo de material faz com que o aluno entenda sobre o que estamos falando, gerando um interesse, curiosidade e melhor assimilação do conteúdo estudado (P1).

Além de produzirmos os modelos em conjunto com algumas turmas da escola onde a pesquisa ocorreu, ao final do trabalho, disponibilizamos os mesmos para outros professores da escola utilizarem com outras turmas, pois, concordamos que a confecção de modelos didáticos não restringe sua utilização somente no dia de sua exposição em sala de aula, podendo o mesmo vir a contribuir no acervo da escola e induzir a curiosidade e criatividade de outras turmas que possam vir a estudar os mesmos conceitos e assim, construir uma alternativa de ensino e aprendizagem continua no decorrer dos semestres escolares (Costa \& Albuquerque, 2017).

Perguntamos ainda a professora se houve uma aceitação por parte dos alunos em relação a metodologia realizada, afirmando:

Sim, os alunos pedem esse tipo de atividade, eles sentem a necessidade de práticas como essas, assim como nós professores de biologia necessitamos. Então quando não há apenas alguma aula introdutória de forma tradicionalista com certeza absoluta há um maior interesse pela disciplina (P1).

Com isso, é perceptível a importância da utilização de recursos didáticos no processo de ensino e aprendizagem tanto para o aluno quanto para o professor. $\mathrm{O}$ aluno acaba tendo maior interesse pelas aulas, tornando o processo de aprendizagem mais fácil e instigante enquanto o professor poderá visualizar de forma mais efetiva os resultados do seu trabalho (Nicola \& Paniz, 2017). Concordamos ainda com Santos et al (2020) quando afirmam que quando os conteúdos curriculares são trabalhados aliando-se a metodologia tradicional com a ludicidade proporcionam a compreensão e, consequentemente, o aprendizado de conhecimentos científicos, tornando-se ferramentas relevantes para o ensino de biologia.

Com os relatos da professora e diante de observações realizadas durante as aulas de aplicação, percebemos que a escolha dos temas a serem abordados nas práticas lúdicas foram bastante válidos e podem ter contribuído de fato para o processo de aprendizagem destes discentes. Para Ferreira e Santos (2019) o lúdico é um dos temas que mais encanta os educadores sem importar o nível de ensino em que estão inseridos, também por afirmar que de alguma maneira a ludicidade acrescenta elementos indispensáveis ao relacionamento com outras pessoas. Proporciona a aproximação entre os alunos e fortalece a relação professor e aluno, pois ao decorrer do desenvolvimento das atividades em conjunto, cria-se um vínculo de segurança e sensação de conforto, consequentemente minimiza-se a pressão do conteúdo e a tensão da sala de aula.

Com relação aos modelos didáticos, destacamos o grande êxito na construção da membrana plasmática, por outro lado, verificamos a necessidade de utilização de outros materias que tornem a prática de divisão celular mais atrativa e consistente. Dentre todas as atividades desenvolvidas, concordamos com a necessidade de reformular esta prática com o objetivo 
de torná-la ainda mais lúdica, substituindo a apresentação após a montagem dos movimentos cromossômicos por algo mais dinâmico.

\section{Conclusão}

As práticas aplicadas reduziram a tensão do ambiente escolar e dinamizaram a apresentação do conteúdo, ressaltando que estas podem favorecer o processo de ensino e aprendizagem dos alunos por complementar a teoria, com isso, o professor precisa saber o que busca e ter objetivos claros dos conteúdos que podem ser explorados através das atividades lúdicas.

As práticas realizadas e a construção dos modelos biológicos, se caracterizaram como importantes aliados no ensino de Biologia, considerando-as de grande importância para a aprendizagem do conteúdo, socialização entre os estudantes, fortalecimento da relação professor-aluno e dinamização do ambiente de sala de aula.

Com o desenvolvimento das atividades, notamos ainda que a falta de estrutura escolar interfere diretamente não só no processo de ensino e aprendizagem, mais também no interesse dos estudantes. No cotidiano escolar, nos deparamos com algumas dificuldades na realização, como: a falta de laboratório ou ambiente adequado para produção de material, atraso no calendário letivo e a falta de determinados materiais didáticos. Desta forma, a opção de utilizar materias reutilizáveis e de baixo custo nas práticas minimizou possíveis outros empecilhos que pudéssemos encontrar.

A ludicidade e a produção dos modelos se mostraram algo inovador nas aulas de biologia por se tratar de uma metodologia totalmente nova na escola ao qual realizamos a aplicação. Isso despertou a curiosidade dos alunos pelo simples motivo de poderem observar, tocar e confeccionar estruturas microscópicas que normalmente são abstratas. Desta forma, compreendemos que a metodologia contribuiu no desenvolvimento cognitivo dos alunos, no rendimento escolar e despertou maior interesse pela disciplina de biologia. No entanto, este estudo não se esgota aqui, sendo necessário mais diálogo sobre a ludicidade no ensino de biologia.

Com o término da pesquisa, o material confeccionado foi disponibilizado para a escola, podendo ser utilizado em outras salas de aula por outros professores. Desta forma, esse tipo de recurso metodológico pode ser utilizado como mais uma ferramenta no ensino de biologia.

Entendemos também que a metodologia pode passar por aperfeiçoamento, outros materiais podem ser utilizados na produção dos modelos biológicos, novos planos podem ser traçados e realizados para aulas lúdicas, nesta e também em outras escolas, para que assim, possam chamar cada vez mais a atenção dos alunos e despertar seu interesse pela disciplina. Além disso, a metodologia pode ser testada no ensino de biologia no formato remoto, onde o professor pode disponibilizar um vídeo explicativo indicando o passo-a-passo e o material necessário, para que os alunos possam construir os modelos diretamente das suas próprias residências, possibilitando maior dinamicidade no ensino de biologia neste formato.

\section{Referências}

Amaral, F. S., Pereira, C. A. S., Vinciprova, M. C., Albuquerque, G. G. \& Silva, I. C. M. (2015). Jogo de transfusão, um recurso lúdico para o ensino de Hematologia a estudantes de enfermagem. Revista Práxis. https://doi.org/10.25119/praxis-7-13-666.

Araújo, A. A. C. \& Santos, S. P. (2014). Olhares para o ensino em Biologia: concepções de estudantes do ensino médio. http://www.uece.br/endipe2014/ebooks/livro1/383.

Borba, J. B. (2013). Uma breve retrospectiva do ensino de biologia no Brasil. (Trabalho de especialização, Universidade Tecnológica Federal do Paraná). http://riut.utfpr.edu.br/jspui/bitstream/1/20730/2/MD_EDUMTE_I_2012_12.pdf.

Cardoso, F. de S. (2013). O uso de atividades no ensino de Ciências: na busca de melhores resultados no processo de ensino aprendizagem. (Monografia, Centro Universitário UNIVATES curso de graduação em Licenciatura em Ciências Biológicas). https://www.univates.br/bdu/bitstream/1073 7/380/1/Fab\%C3\%ADola\%20de\%20SouzaCardoso.pdf.

Cardozo, L. T., Miranda, A. S., Moura, M. J. C. S. \& Marcondes, F. K. (2016). Effect of a puzzle on the process of students' learning about cardiac physiology. Advances in Physiology Education. https://doi.org/10.1152/advan.00043.2016. 
Cartaxo, N. P. de A. (2013). A Influência do Lúdico no Ensino de Biologia. Webartigos. https://www.webartigos.com/artigos/a-influencia-do-ludico-no-ensinode-biologia/109300.

Costa, B. N., De Albuquerque, A. K. M. \& Sousa, M. Z. S. (2017). Modelos didáticos como ferramenta para o ensino de biologia celular: um relato de caso no ensino médio em Parnaíba-PI. In: Costa et al. (Anais). V Congresso Nacional de Pesquisa e Ensino de Ciências - PI, Teresina: Anais... Teresina: Universidade Federal do Piauí, p. 1-11.

Costa, W. da C. \& Pinho, K. E. P. (2008). A Importância e a Contribuição do Lúdico no Processo Educacional. Portal Educacional do Estado do Paraná. http://www.diaadiaeducacao.pr.gov.br/portals/pde/arquivos/1681-8.pdf.

De Oliveira, A. C. S., Braga, B. L. P., Do Nascimento, M. M. B., Cavalcante, C. C. \& Sobreira, A. C. de M. (2015). Modelos didáticos como recurso para o ensino de biologia: uma experiência didático-pedagógica com alunos do ensino médio de uma escola pública de Iguatu/Ce. In: De Oliveira et al. (Anais). XII Congresso Nacional de Educação - PR, Curitiba: 2015. Anais... Curitiba: Pontifica Universidade Católica do Paraná, p. 78-91.

Nascimento, R. G., De Oliveira, N. C. R., De Oliveira, F. C. S., Lopes, A. C. de A. \& Fraga, E. da C. (2020). Prática lúdica "DNA recombinante” e sua influência na percepção e no conhecimento de estudantes sobre biotecnologia e enzimas de restrição. Revista Experiências em Ensino de Ciências. https://if.ufmt.br/eenci/artigos/Artigo_ID723/v15_n2_a2020.pdf.

Duré, R. C., Andrade, M. J. D. \& Abílio, F. J. P. (2018). Ensino de biologia e contextualização do conteúdo: quais temas o aluno de ensino médio relaciona com o seu cotidiano. Experiências em Ensino de Ciências. https://if.ufmt.br/eenci/artigos/Artigo_ID471/v13_n1_a2018.pdf.

Ferreira, A. A. dos S. N. \& Dos Santos, C. B. (2019). A Ludicidade no Ensino da Biologia. Revista de psicologia. https://idonline.emnuvens.com.br/id/article/view/1749/2586.

Freire, P. (1996). Pedagogia da autonomia: saberes necessários para a prática educativa. Paz e Terra.

Krasilchik, M. (2008). Prática de Ensino de Biologia. Editora da Universidade de São Paulo - USP.

Mehes, R. \& Maistro, V. I. de A. (2011). A contribuição dos conceitos transmitidos pelas charges e quadrinhos para a aprendizagem da Biologia. In: Mehes, R. \& Maistro, V. I. de A. (Anais). X Congresso Nacional de Educação - PR, Curitiba: 2011. Anais... Curitiba: Pontifica Universidade Católica do Paraná, p. 119132

Nascimento, M. S. B., Silva, C. H., Fernandes, E. F., Dantas, F. K. da S. \& Sobreira, A. C. de M. (2015). Desafios à prática docente em biologia: o que dizem os professores do ensino médio. In: Nascimento et al. (Anais). XII Congresso Nacional de Educação - PR, Curitiba: 2015. Anais... Curitiba: Pontifica Universidade Católica do Paraná, p. 1-14.

Nicola, J. A. \& Paniz, C. M. (2017). A importância da utilização de diferentes recursos didáticos no ensino de biologia. Revista NEaD-Unesp. https://ojs.ead.unesp.br/index.php/nead/article/view/InFor2120167/pdf.

Orlando, T.C., Lima, A. R., Da Silva, A. M., Fuzissaki, C. N., Ramos, C. L., Machado, D., Fernandes, F. F. F., Lorenzi, J. C. C., De Lima, M. A., Barbosa, S. G. V. C. \& Tréz, T. A. (2009). Planejamento, montagem e aplicação de modelos didáticos para abordagem de Biologia Celular e Molecular no Ensino Médio por graduandos de Ciências Biológicas. Revista de Ensino de Bioquímica. http://bioquimica.org.br/revista/ojs/index.php/REB/article/view/33.

Pereira, R. J. B., Azevedo, M. M. R., Sousa, E. T. F. \& Hage, A. X. (2020). Método tradicional e estratégias lúdicas no ensino de biologia para alunos de escola rural do município de Santarém-Pa. Revista Experiências em Ensino de Ciências. https://if.ufmt.br/eenci/artigos/Artigo_ID717/v15_n2_a2020.pdf.

Porto, A., Ramos, L. \& Goulart, S. (2009). Um olhar comprometido com o ensino de ciências. Fapi.

Santos, S. B., Azevedo, M. M. R., Cavalcante, I. A. P. \& Hager, A. X. (2020). Jogos didáticos no ensino de biologia na EJA em escolas públicas de Santarém/Pa. Revista Experiências em Ensino de Ciências.

Silva, K. J. De O., Teixeira, C. \& Pereira, F. L. (2020). Construção e utilização de modelos didáticos de Pediculus humanus capitis para discussão sobre pediculose em uma escola do campo. Revista Experiências em Ensino de Ciências. https://if.ufmt.br/eenci/artigos/Artigo_ID687/v15_n1_a2020.pdf.

Soares, S. de J. (2019). Pesquisa Científica: Uma abordagem sobre o método qualitativo. Revista Ciranda, 1 (3),168-180.

Tesori, S. P. \& Martins, D. T. L. (2018). Produção de materiais pedagógicos como estratégia de ensino de biologia. (Trabalho de conclusão de curso - Instituto Federal Catarinense, Campus avançado Abelardo luz). http://abelardoluz.ifc.edu.br/wp-content/uploads/2019/03/TC-Suzana.pdf. 